\title{
Dyslipidemia among Sudanese Children Undergoing Maintenance Dialysis
}

\author{
El-Tigani Mohamed Ali*, Salma Mamoun Ahmed, Mohamed B Abdelraheem
}

Pediatric Nephrology Department, Soba University Hospital, Khartoum, Sudan

\begin{abstract}
Introduction: Dyslipidemia is an established risk factor for atherosclerosis and cardiovascular disease. It is common among children undergoing maintenance dialysis. To our knowledge, this is the first report on the lipid profile of children undergoing maintenance hemodialysis (HD) or continuous ambulatory peritoneal dialysis (CAPD) in Sudan.
\end{abstract}

Methods: We studied 17 children on HD, 11 children on CAPD and 28 controls. The levels of total cholesterol (TC), triglycerides (TGD) and high density lipoprotein cholesterol (HDL-C) were measured from fasting serum samples using electrophoresis and low density lipoprotein cholesterol (LDL-C) was then calculated.

Results: End stage renal failure (ESRF) children had higher mean TC $(193 \pm 36$ versus $135 \pm 17 \mathrm{mg} / \mathrm{dl})$, higher mean TGD (120 \pm 38 versus $90 \pm 15 \mathrm{mg} / \mathrm{dl})$, higher mean LDL-C (129 \pm 32 versus $69 \pm 18 \mathrm{mg} / \mathrm{dl})$, and lower mean HDL-C ( $39 \pm 12$ versus $49 \pm 4 \mathrm{mg} / \mathrm{dl})$ than controls $(\mathrm{P}=0.00$ for all parameters). CAPD patients had higher mean TC $(211 \pm 39$ versus $181 \pm 30 \mathrm{mg} / \mathrm{dl})$ and higher LDL-C $(145 \pm 35$ versus $118 \pm 25 \mathrm{mg} / \mathrm{dl})$ than controls $(\mathrm{P}=0.03$ for both parameters). The prevalence of dyslipidemia among ESRF patients was $75 \%$ while none of the control group had lipid parameters outside the accepted range. Among ESRF patients, $39.3 \%$ had TC $>200 \mathrm{mg} / \mathrm{dl}, 21.4 \%$ had TGD $>150 \mathrm{mg} / \mathrm{dl}, 42.9 \%$ had LDL-C $>130 \mathrm{mg} / \mathrm{dl}$, and $35.7 \%$ had HDL-C $<35 \mathrm{mg} / \mathrm{dl}$. Abnormal HDL-C values were more prevalent among CAPD patients compared to HD patients $(52.9 \%$ versus $9.1 \%, \mathrm{P}=0.02)$

Conclusion: Despite the small number of studied children, this study is likely to reflect the high prevalence of dyslipidemia among children undergoing maintenance dialysis treatment in Sudan.

\footnotetext{
* Corresponding author; Pediatric department, Soba University Hospital, University of Khartoum, PO Box 102, Khartoum, Sudan E mail: dreltigani@hotmail.com
}

Keywords: Children; Continuous Ambulatory Peritoneal Dialysis; Dyslipidemia; Hemodialysis; Sudan

\section{The authors declared no conflict of interest}

\section{Introduction}

Improvement in dialysis adequacy has increased the survival of pediatric patients on maintenance dialysis. With increasingnumbersoflong-termsurvivorsundergoingsuch treatment, complications like dyslipidemia are becoming more frequent. Dyslipidemias are disorders of lipoprotein metabolism that result in excess total cholesterol (TC), excess low-density lipoprotein cholesterol (LDL-C), excess triglyceride (TGD), or deficiency of high-density lipoprotein cholesterol (HDL-C). Dyslipidemia patterns similar to familial hypertriglyceridemia or type IV hyperlipidemia were found to be common in pediatric patients undergoing chronic dialysis treatment [1-4]. There are many factors which may contribute to the risk of dyslipidemia in chronic dialysis patients, such as a diet rich in fat and carbohydrates [1], medications [5], use of high molecular weight heparin [6], decrease in lipoprotein lipase level [1], high glucose content of dialysate [7] and L-carnitine deficiency [1]. This early onset of childhood dyslipidemia together with prolonged survival of ESRF children having adequate dialysis, may subject these patients to high risk of complications including premature coronary artery disease [1, 8-10]. Moreover, such dyslipidemia may persist even after successful renal transplantation [11].

Although conclusive data regarding the risks and the benefits of treatment of dyslipidemia are lacking, early detection, prevention and probably treatment are recommended in this population of children. There is no study to date to show the effect of chronic dialysis on the lipid profile of pediatric ESRF patients in Sudan. The aim of this study was to determine the lipid profile of a group of Sudanese end stage renal failure (ESRF) pediatric patients maintained on hemodialysis (HD) or continuous ambulatory peritoneal dialysis (CAPD) in comparison to a control group. 
Table 1: Demographic and clinical characteristics of studied children

\begin{tabular}{llll}
\hline Characteristics & Controls (28) & HD (17) & CAPD (11) \\
\hline Age in years (mean \pm SD) & $9 \pm 1.9$ & $12.7 \pm 3.8$ & $10.3 \pm 4.5$ \\
Age range & $6-12$ & $4-17$ & $4-17$ \\
Male gender (\%) & 35.7 & 70.6 & 63.6 \\
BMI age centile (mean \pm SD) & $56.9 \pm 26.9$ & $11.8 \pm 21.9$ & $15.5 \pm 18.9$ \\
BMI Z-score (mean \pm SD) & $0.2 \pm 0.8$ & $-2.9 \pm 2.7$ & $-3.3 \pm 3.6$ \\
Dialysis duration in months (mean \pm SD) & - & $14.8 \pm 18.5$ & $7.2 \pm 7.7$ \\
\hline
\end{tabular}

Table 2: Comparison of lipid parameters between ESRF patients and controls (mean \pm SD)

\begin{tabular}{llll}
\hline Lipid parameter & Control & ESRF & P value \\
\hline TC & $135.2 \pm 17.3$ & $192.8 \pm 36.2$ & $0.00 *$ \\
TGD & $90.2 \pm 14.9$ & $120 \pm 38$ & $0.00 *$ \\
LDL-C & $68.8 \pm 17.6$ & $128.8 \pm 31.6$ & $0.00 *$ \\
HDL-C & $49.1 \pm 3.5$ & $39.4 \pm 11.5$ & $0.00 *$ \\
\hline
\end{tabular}

* Statistically significant

\section{Methods}

A total of 56 children (28 ESRF patients and 28 controls) were enrolled in the study. Data were collected between December 2006 and May 2007. ESRF patients were recruited from two renal centers in Khartoum, Sudan; the first center is a specialized pediatric renal center based in Soba University Hospital while the other is an independent renal unit that cares for adult and pediatric ESRF patients and lacks a pediatric nephrologist. The ESRF group included 17 patients on maintenance HD and 11 patients on CAPD, all of whom were on treatment for at least 3 months. CAPD patients were managed in adherence to the International Society of Peritoneal Dialysis (ISPD) guide-lines [12]. HD patients were dialysed using appropriate-size dialysers and received three four-hourly sessions of HD per week. Informed consent was obtained from children's parents. Data pertaining to age, gender, duration of dialysis and body mass index z-score (BMI z-score) was collected. After 10-hours overnight fasting, heparinized venous blood samples were collected. The overnight fast imposed no severe restrictions on the children because most of our children do not have meals between 9-10 pm and 7-8 am. The levels of TC, TGD and HDL-C were measured using electrophoresis. Very low density lipoprotein cholesterol (VLDL-C) levels were calculated using the equation:

$\mathrm{VLDL}-\mathrm{C}=\mathrm{TGD} / 5$

LDL-C was then calculated using the equation:
LDL-C $=\mathrm{TC}-($ HDL-C + VLDL-C) [13]

The National Cholesterol Education Program (NCEP) report recommends using the same cut points to identify children and adolescents with abnormal lipid and lipoprotein concentrations, from 2 to 18 years of age [14]. For the purpose of this study, dyslipidemia was defined by TC levels $>200 \mathrm{mg} / \mathrm{dl}$, LDL-C levels $>130 \mathrm{mg} / \mathrm{dl}$, TGD levels $>150 \mathrm{mg} / \mathrm{dl}$ or HDL-C levels $<35 \mathrm{mg} / \mathrm{dl}$ in accordance with the NCEP group [14] and the American Heart Association guidelines [15].

Data was analysed using Statistical Package for Social Sciences (SPSS) version 11.5. Lipid profiles of the two groups were expressed as mean $\pm \mathrm{SD}$ and compared using Student's t-test. Chi-squared test was used to examine the association between dyslipidemia and different clinical parameters. $\mathrm{P}$ value less than 0.05 was considered as significant.

\section{Results}

The study included 28 ESRF patients. The cause of renal failure was obstructive uropathy in eight children (28.5\%), glomerulonephritis in three children (10.7), metabolic disorders in two children $(7.2 \%)$, sickle cell nephropathy in one child $(3.6 \%)$, and unknown in the remainder. Demographic and clinical characteristics of studied children are shown (Table 1). Children in the ESRF group were older, more commonly females and had lower BMI compared to the control group, but there 
Table 3: Comparison of lipid parameters between patients undergoing HD and CAPD (mean \pm SD)

\begin{tabular}{llll}
\hline Lipid parameter & HD & CAPD & P value \\
\hline TC & $180.9 \pm 29.7$ & $211.2 \pm 39.1$ & $0.03 *$ \\
TGD & $115 \pm 30.3$ & $127.8 \pm 48.2$ & 0.39 \\
LDL-C & $118.4 \pm 25.3$ & $144.8 \pm 34.8$ & $0.03 *$ \\
HDL-C & $37.5 \pm 13.5$ & $42.5 \pm 6.7$ & 0.27 \\
\hline
\end{tabular}

* Statistically significant

Table 4: Prevalence of abnormalities in lipid parameters among ESRF patients (\%)

\begin{tabular}{llll}
\hline Lipid parameter & HD & CAPD & P value \\
\hline TC $>200 \mathrm{mg} / \mathrm{dl}$ & 35.3 & 45.5 & 0.4 \\
$\mathrm{TGD}>150 \mathrm{mg} / \mathrm{dl}$ & 11.8 & 36.4 & 0.1 \\
$\mathrm{LDL}-\mathrm{C}>130 \mathrm{mg} / \mathrm{dl}$ & 35.3 & 54.5 & 0.3 \\
HDL-C $<35 \mathrm{mg} / \mathrm{dl}$ & 52.9 & 9.1 & $0.02 *$ \\
Dyslipidemia & 76.5 & 72.7 & 0.6 \\
\hline
\end{tabular}

* Statistically significant

were no significant differences between HD and CAPD patients.

ESRF patients had significantly higher TC, TGD, LDL-C and lower HDL-C values compared to controls (Table 2). CAPD patients had significantly higher TC and LDL-C values compared to HD patients (Table 3).

Age, gender and BMI z-score were not correlated to lipid profile values in the control group. Gender, BMI z-score and dialysis duration had no correlation to lipid profile in the ESRF group. Age had a weak negative correlation with HDL-C $(\mathrm{R}=-0.43, \mathrm{P}<0.05)$ in the ESRF group, but was not correlated to other lipid parameters.

The prevalence of dyslipidemia among ESRF patients was $75 \%$ while none of the control group had lipid parameters outside the accepted range. Among ESRF patients, $39.3 \%$ had TC $>200 \mathrm{mg} / \mathrm{dl}, 21.4 \%$ had TGD $>$ $150 \mathrm{mg} / \mathrm{dl}, 42.9 \%$ had LDL-C $>130 \mathrm{mg} / \mathrm{dl}$, and $35.7 \%$ had HDL-C $<35 \mathrm{mg} / \mathrm{dl}$. Abnormal HDL-C values were more prevalent among CAPD patients compared to HD patients, but the prevalence of other parameters was not significantly different between the two groups (Table 4)

\section{Discussion}

Evaluation of dyslipidemia in children is complicated by the known age, sexual, and ethnic differences in lipid concentrations. In the 1988-1994 National Health and Nutrition Examination Surveys (NHANES), age specific values for mean TC were found to peak at 9-11 years of age, subsequently decrease during pubertal development and then increase thereafter [16]. Females were found to have higher TC and LDL-C concentrations than males, and tended to have higher HDL-C concentrations than males after pubertal development [16]. In the same report, black children were found to have higher HDL-C and lower TGD concentrations than children of non-Hispanic white and Hispanic descent [16]. In the Cardiovascular Health in Children Study of 8-10 year-olds in North Carolina, $18.7 \%$ of black children had TC $>200 \mathrm{mg} / \mathrm{dl}$ compared with $11 \%$ of white children [17]. Compared to the reported values of American children and adolescents [16], our control group displayed lower mean TC (135 $\mathrm{mg} / \mathrm{dl}$ versus $160 \mathrm{mg} / \mathrm{dl})$ and lower LDL-C (69 mg/dl versus $100 \mathrm{mg} / \mathrm{dl}$ ). However, this small group may not accurately represent the local population.

Disturbances of lipid metabolism in children with chronic renal failure had been reviewed by Querfeld in 1993 [4]. He reported that uremic dyslipidemia characterised by high TGD and low HDL-C serum levels was present in the majority of patients whereas levels of $\mathrm{TC}$, LDL-C and VLDL-C were frequently elevated. In this study, we found that this group of pediatric patients on maintenance dialysis have approximately similar pattern of dyslipidemia as described above. Similar observations have been made by many other investigators. Pennisi et al [10], Papadopoulou et al [18], and Asayama et al [19] have reported high levels of serum TGD in the majority of their children patients on maintenance HD (93\%, 63\% 
and $100 \%$ respectively). Significantly elevated levels of serum TC were reported in two of these studies [10, 18]. Likewise, high serum levels of TC and TGD have been reported in pediatric patients undergoing peritoneal dialysis in many previous studies [3, 20-22]. Alterations in lipid profiles were often found to be more pronounced in PD patients than HD patients [22-25]. However, some studies observed no such difference in serum lipids on either type of dialysis treatments [20]. In this series we demonstrated significantly higher TC and LDL-C in CAPD compared to HD patients.

\section{Conclusion}

Despite the small number of studied children, this study is likely to reflect the situation among children undergoing maintenance dialysis treatment in Sudan. Dyslipidemia was found to be very common in this group of ESRF patients.

\section{Acknowledgement}

This work is part of a thesis submitted for partial fulfilment of clinical MD in Pediatrics, University of Khartoum (2007).

\section{References}

1. Fine RN, Whyte DA, Boydstun II. Conservative management of chronic renal insufficiency. In: Avner ED, Harmaon WE, Niaudet P, editors. Pediatric nephrology. 5th ed. Philadelphia: Lippincott Williams \& Wilkins; 2004. P. 1291-311.

2. Kidney Disease Outcomes Quality Initiative (K/ DOQI) Group. K/DOQI clinical practice guidelines for management of dyslipidemias in patients with kidney disease. Am J Kidney Dis. 2003 Apr;41(4 Suppl 3):I-IV, S1-91.

3. Querfeld U, Salusky IB, Nelson P, Foley J, Fine RN. Hyperlipidemia in paediatric patients undergoing peritoneal dialysis. Pediatr Nephrol. 1988 Oct;2(4):44752.

4. Querfeld U. Disturbances of lipid metabolism in children with chronic renal failure. Pediatr Nephrol. 1993 Dec;7(6):749-57

5. Singh A, Tejani A. Hyperlipidemia in children: the role of uremia, steroids and cyclosporine therapy. Nephron. 1996;74(3):529-35.

6. Elisaf MS, Germanos NP, Bairaktari HT, Pappas MB, Koulouridis EI, Siamopoulos KC. Effects of conventional vs. low-molecular-weight heparin on lipid profile in hemodialysis patients. Am J Nephrol. 1997;17(2):153-7.
7. Swamy AP, Cestero RV, Campbell RG, Freeman RB. Long-term effect of dialysate glucose on the lipid levels of maintenance hemodialysis patients. Trans Am Soc Artif Intern Organs. 1976;22:54-9.

8. Ross R. The pathogenesis of atherosclerosis: an update. N Engl J Med. 1986 Feb 20;314(8):488-500.

9. Grundy SM. Cholesterol and coronary heart disease. A new era. JAMA. 1986 Nov 28;256(20):2848-58.

10. Pennisi AJ, Heuser ET, Mickey MR, Lipsey A, Malekzadeh MH, Fine RN. Hyperlipidemia in pediatric hemodialysis and renal transplant patients. Associated with coronary artery disease. Am J Dis Child. 1976 Sep;130(9):957-61.

11. Silverstein DM, Palmer J, Polinsky MS, Braas C, Conley SB, Baluarte HJ. Risk factors for hyperlipidemia in long-term pediatric renal transplant recipients. Pediatr Nephrol. 2000 Feb;14(2):105-10.

12. Watson AR, Gartland C; European Paediatric Peritoneal Dialysis Working Group. Guidelines by an Ad Hoc European Committee for Elective Chronic Peritoneal Dialysis in Pediatric Patients. Perit Dial Int. 2001 MayJun;21(3):240-4.

13. Tietz NW. Method of the estimation of lipoprotein concentration without ultracentrifugation. In: Tietz NW, editor. Tietz Fundamentals of Clinical Chemistry. 2nd ed. Philadelphia: W.B. Saunders company; 1976. 1263 p.

14. American Academy of Pediatrics. National Cholesterol Education Program: Report of the Expert Panel on Blood Cholesterol Levels in Children and Adolescents. Pediatrics. 1992 Mar;89(3 Pt 2):525-84.

15. Kavey RE, Daniels SR, Lauer RM, Atkins DL, Hayman LL, Taubert K; American Heart Association. American Heart Association guidelines for primary prevention of atherosclerotic cardiovascular disease beginning in childhood. Circulation. 2003 Mar 25;107(11):1562-6.

16. Hickman TB, Briefel RR, Carroll MD, Rifkind BM, Cleeman JI, Maurer KR, Johnson CL. Distributions and trends of serum lipid levels among United States children and adolescents ages 4-19 years: data from the Third National Health and Nutrition Examination Survey. Prev Med. 1998;27(6):879-90.

17. Bradley CB, Harrell JS, McMurray RG, Bangdiwala SI, Frauman AC, Webb JP. Prevalence of high cholesterol, high blood pressure, and smoking among elementary school children in North Carolina. N C Med J. 1997;58(5):362-7.

18. Papadopoulou ZL, Sandler P, Tina LU, Jose PA, Calcagno PL. Hyperlipidemia in children with chronic renal insufficiency. Pediatr Res. 1981 Jun;15(6):887-91. 
19. Asayama K, Ito H, Nakahara C, Hasegawa A, Kato K. Lipid profiles and lipase activities in children and adolescents with chronic renal failure treated conservatively or with hemodialysis or transplantation. Pediatr Res. 1984 Aug;18(8):783-8.

20. Berger M, James GP, Davis ER, Jasper PM, Brouhard BH, Travis LB, Cunningham RJ. Hyperlipidemia in uremic children: response to peritoneal dialysis and hemodialysis. Clin Nephrol. 1978 Jan;9(1):19-24.

21. Scolnik D, Balfe JW. Initial hypoalbuminemia and hyperlipidemia persist during chronic peritoneal dialysis in children. Perit Dial Int. 1993;13(2):136-9.

22. Müller T, Koeppe S, Arbeiter K, Luckner D, Salzer U, Balzar E, Aufricht C. Serum lipid pattern unifies following renal transplantation in children. Pediatr Nephrol. 2003 Sep;18(9):939-42.
23. Cattran DC, Fenton SS, Wilson DR, Steiner G. Defective triglyceride removal in lipemia associated with peritoneal dialysis and haemodialysis. Ann Intern Med. 1976 Jul;85(1):29-33.

24. Chan MK, Varghese Z, Persaud JW, Baillod RA, Moorhead JF. Hyperlipidemia in patients on maintenance hemo- and peritoneal dialysis: the relative pathogenetic roles of triglyceride production and triglyceride removal. Clin Nephrol. 1982 Apr;17(4):183-90.

25. Avram MM, Goldwasser P, Burrell DE, Antignani A, Fein PA, Mittman N. The uremic dyslipidemia: a crosssectional and longitudinal study. Am J Kidney Dis. 1992 Oct;20(4):324-35. 